\title{
AC 2012-5096: DESIGING THE PATHWAYS OF ENGINEERING ALUMNI RESEARCH SURVEY (PEARS)
}

Dr. Helen L. Chen, Stanford University

Ms. Michelle Marie Grau, Stanford University

Michelle Grau is a junior in mechanical engineering at Stanford University, and was one of the students in the first revision of ENGR 14, Introduction to Solid Mechanics. Her research interests include engineering education, robotics in space applications, and using robots to introduce engineering to middle school students. She is passionate about the FIRST Robotics program, in which she coaches teams and volunteers at competitions. She also does wushu and gymnastics.

\section{Ms. Samantha Ruth Brunhaver, Stanford University}

Samantha Brunhaver is a fourth-year graduate student at Stanford University. She is currently working on her Ph.D. in mechanical engineering with a focus in engineering education. Brunhaver completed a B.S. in mechanical engineering from Northeastern University in 2008 and a M.S. in mechanical engineering with a focus in design for manufacturing from Stanford in 2010.

\section{Dr. Shannon Katherine Gilmartin \\ Dr. Sheri Sheppard, Stanford University}

Sheri Sheppard, Ph.D., P.E., is professor of mechanical engineering at Stanford University. Besides teaching both undergraduate and graduate design and education-related classes at Stanford University, she conducts research on weld and solder-connect fatigue and impact failures, fracture mechanics, applied finite element analysis, and engineering education. In addition, from 1999-2008, she served as a Senior Scholar at the Carnegie Foundation for the Advancement of Teaching, leading the Foundation's engineering study (as reported in Educating Engineers: Designing for the Future of the Field). Sheppard's graduate work was done at the University of Michigan.

\section{Michelle Warner, Stanford University}




\title{
Designing the Deployment of the Pathways of Engineering Alumni Research Survey (PEARS)
}

\begin{abstract}
Surveys of engineering alumni are a common approach taken by departments to collect evidence demonstrating how educational objectives are being met for the purpose of continuous improvement of the program (ABET Criterion 4). While survey administration tools have become widely available and easy to navigate, researchers must still address the challenges of designing not only a concise survey instrument but also an effective deployment plan that results in a high response rate among targeted respondents.
\end{abstract}

To explore these issues in a real world context, this paper draws upon first hand experiences related to the planning of the Pathways of Engineering Alumni Research Survey (PEARS) which was piloted with geographically distributed engineering alumni from four institutions in fall 2011. Creating the PEARS deployment plan paralleled the design of the instrument itself. This paper speaks to the unique logistical considerations of deploying an alumni survey with respect to subject recruitment, incentives, alumni association partnerships, and scalability. The preliminary findings outlined here are intended to inform the redesign of the deployment plan for future administrations of PEARS as well as to serve as a practical resource for other researchers wishing to survey engineering alumni.

\section{Introduction}

Surveys of engineering alumni are a common approach taken by departments to collect evidence demonstrating how educational objectives and students are being met for the purpose of continuous improvement of the program (ABET Criterion 4). While survey administration tools have become widely available and easy to navigate, researchers must still address the challenges of designing not only a concise survey instrument but also an effective deployment plan that results in a high response rate among targeted respondents. Although there is extensive research on both survey instrument design as well as strategies to increase response rates, this paper specifically applies these approaches to surveys of engineering alumni, particularly early career professionals (ECPs) who are within five years of graduation from their undergraduate institutions.

To establish a context for exploring the issues and challenges related to surveying engineering alumni, we draw upon our experiences with the Pathways of Engineering Alumni Research Survey (PEARS) which was piloted with geographically distributed engineering alumni from four institutions in fall 2011. Designed in summer 2011 as part of the broader NSF-funded Engineering Pathways Study, PEARS builds upon the prior work of the Academic Pathways of People Learning Engineering Survey (APPLES) that was deployed to over 4,500 undergraduate engineering students at 21 institutions (Chen et al., 2008; Donaldson et al., 2007; Donaldson et al., 2008).

The anticipated findings from PEARS will: 1) inform the field's understanding about how the college experience advances engineering students' development as ECPs and their conceptions 
of and preparations for their specific careers; 2) identify the educational and workplace factors, or combinations of factors, that most influence the development of engineering students into successful ECPs; and 3) illuminate the pathways of early ECPs in terms of planning and preparing to meet future career goals and overcome challenges. Framing the purpose and objectives of PEARS in ways that would resonate with alumni was critical in the design of all communications with survey respondents.

\section{Benefits and Limitations of Surveying Alumni}

The design of the PEARS deployment plan was informed by perspectives from scholars in institutional research and alumni relations. Ewell (2005) documents the history of surveying the graduates of American colleges and universities back to the 1930s when longitudinal studies of former students through the Great Depression and World War II were not uncommon. With the rise of institutional research programs in the 1960s (Olsen, 2002), the focus of alumni surveys transitioned from improvement of student services and instruction to an emphasis on accountability and educational outcomes in a "return on investment" context as seen in recent decades. For example, alumni perspectives on undergraduate educational experiences are a required component of ABET accreditation.

Cabrera et al. (2005) describes three specific applications of alumni surveys used to capture alumni perspectives regarding how well their institution prepared them for the workforce (alumni outcomes approach), how the formal and informal undergraduate experiences contributed to the alumni's current skills and abilities (engagement and competencies approach), and alumni's willingness to support institutional interests (alumni giving). While the emphasis of the PEARS instrument is in the former two areas, Cabrera et al. identifies additional audiences beyond the usual faculty and departmental leadership which led to discussions about the practical implications of PEARS for prospective students and parents, current students, and alumni associations.

By its very nature, alumni survey data is characterized by uncertainty due to commonly small sample sizes and low response rates. The credibility of respondent self-reports can also become more tenuous as the time since degree lengthens, especially when asking alumni to recall what courses they took or the impact of other educational experiences they had back in college. (Ewell, 2005) Most state-sponsored alumni surveys are typically administered within five years of graduation which is in line with the time frame and target population for PEARS.

Another limitation of an alumni survey such as PEARS with a focus on the relationship between college experiences and workforce preparation was identified in findings from Pike's 1990 survey of University of Tennessee graduates which suggest that current career achievements of alumni can influence their perceptions and ratings of collegiate experiences (Pike, 2004). In preparing to share PEARS findings with audiences such as students, parents, faculty, and the public, these limitations for the interpretation and implications of this work should be recognized (Cabrera et al., 2005). 


\section{Creating the PEARS Deployment Plan}

\section{Partnering with Alumni Associations}

In planning for PEARS, the development of the plan for survey deployment and logistics paralleled the design of the survey instrument itself. While our team possessed experience in deploying national online surveys to students at geographically distributed institutions through our APPLES work, we did not have firsthand knowledge or background on how to effectively reach our target audience of engineering alumni.

The approach we took in PEARS was to first establish partnerships with the local alumni associations at the four institutions that participated in the PEARS pilot. Each institution - one private research university and three public research universities -- had varying infrastructures and resources for alumni outreach. At each school, we worked with a faculty member who helped facilitate the introduction to the alumni contacts and with their support (and sometimes with the engineering dean's as well), we were able to get lists of the names and contact information for engineering alumni from the class of 2007.

This email database of alumni is the foundation of many successful alumni surveys. The quality of the list such as how up to date it is and the accuracy of the email addresses can greatly affect the response rate. We sent an initial "PEARS is coming" mailing to 1,896 email addresses across the four institutions in order to test the "quality" of the alumni email lists by tracking the number of "bounce backs" in email addresses. While we did not remove any email addresses from our database, 95 emails"bounced" (representing a range of 0 to $12 \%$ for each of the schoolspecific lists and an average of 5\% across the four schools) It is difficult and time consuming to determine whether an individual email bounce back actually indicates a "bad" email address, especially since even if an email appears to have been received, it may have been sent to an account that is defunct or not frequently checked. In future PEARS deployments, we would like to explore other ways of reaching alumni - particularly young alumni - through social networking tools, clubs and sub groups, etc. rather than relying solely on email lists.

\section{Increasing Response Rates}

Survey fatigue has been a growing concern for all forms of survey research (Ewell, 2005; Porter, 2005; Peltz, 2012) and especially in higher education. Perkins (2011) cites several researchbased best practices shown to increase response rates including the use of incentives, increasing the number of contacts with participants (e.g. reminders and follow-ups after the initial invitation), as well as carefully crafting invitations and contacts so as to convey the trustworthiness of the sender.

In order to maximize response rates and response quality among the PEARS alumni respondents, efforts were focused on three areas: 1) subject recruitment; 2) incentives; and 3) timing of survey launch and reminders, and duration of deployment. Because length of the survey is another critical factors affecting response rate, the survey was piloted repeatedly to determine an accurate and as concise a completion time as possible. 


\section{Subject Recruitment}

Whereas much is understood about undergraduate students, where they live, and how to reach them, the research on surveying alumni populations is somewhat limited although were able to generalize from and modify some of the strategies used with non-college student populations.

An iterative design of the recruitment emails was employed in order to identify the specific issues and approach would resonate with alumni, emphasizing their connections to the institution. The snapshot in Figure 1 represents an early draft of the initial recruitment email with comments linking specific statements to documented research strategies for increasing response rates.

\section{Figure 1. Early version of initial recruitment email}

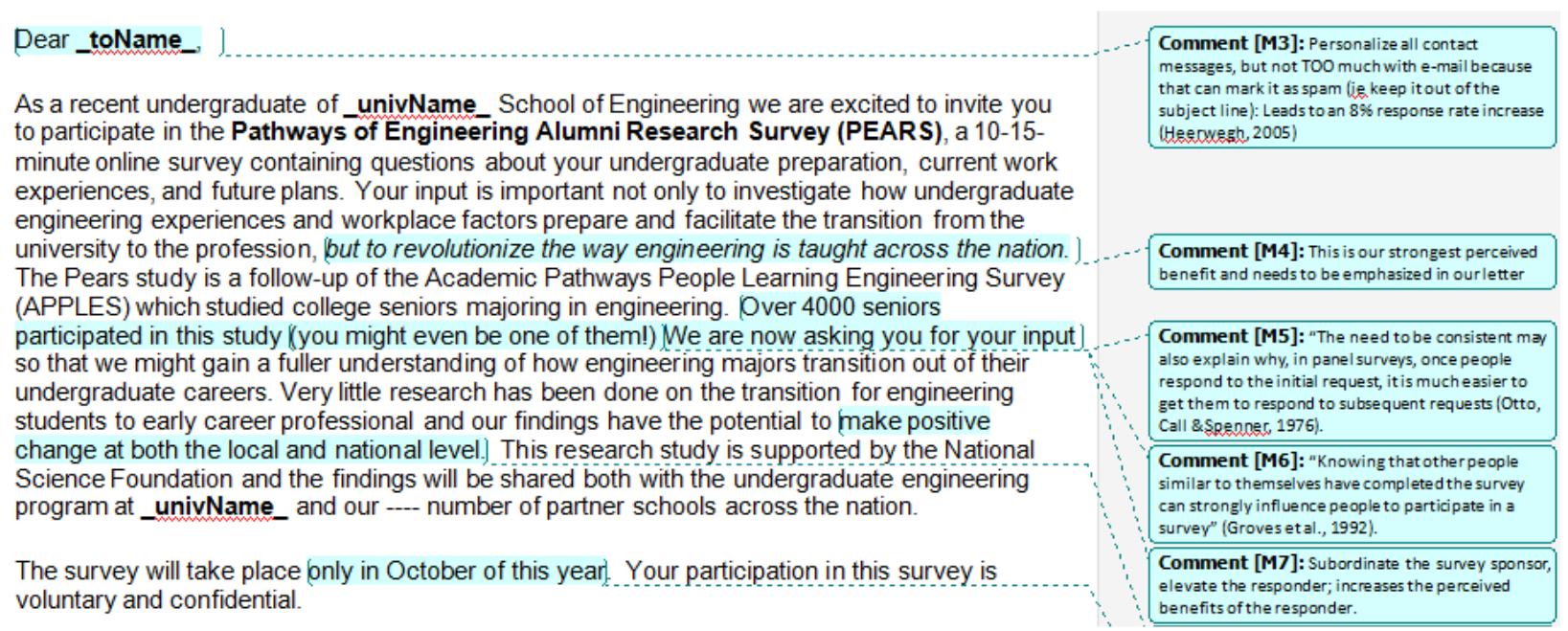

The final version of the initial recruitment email (in Figure 2) was addressed to each alumnus by first name from a senior faculty member, and included a school logo. These elements were included in order to decrease the possibility of the email being seen as spam and to emphasize the alumni's connection to the institution. Joinson and Reips (2007) found that messages sent from recognized officials can increase response rates. As such we later included school logos and small head shots of the senior faculty sending the email, as well as links to their faculty bios and home pages in the follow up reminders, with the idea that the recipient could see that the survey request was coming from an actual person. Seeing the face of the person making the request would be more motivating than a blanket email from an invisible entity. In addition, our choice of Qualtrics, a web-based tool for creating and conducting online surveys and for which our institution has a site license, was also based on the wide range of features now available to personalize the emails to address alumni by name and offer customized survey links where a respondent could start the survey, save their responses in progress, and return to complete it later. 


\title{
Figure 2. Final version of initial recruitment email
}

\author{
The Pathways of Engineering Alumni Research Survey (PEARS) is now open! And your input is of \\ critical importance.
}

Last week we emailed you to inform you about PEARS, a 15-20 minute online survey exploring how undergraduate engineering experiences and workplace factors prepare and facilitate the transition from the university to the workforce. Very little research has been done on this transition for engineering student to early career professional and as a result, we are eager to learn from your personal experiences as a recent graduate.

PEARS is supported by the National Science Foundation. The findings will be shared both with the undergraduate engineering programs at [School1] and at our partner institutions - [School 2], [School 3], and [School 4].

By sharing your views on your undergraduate preparation at [School 1], current work experiences, and future plans in PEARS, you will inform this much-needed area of research and revolutionize how engineering is taught at both the local and national level. We need your help in order to truly understand the impact and the value of the undergraduate engineering experience at [School 1].

To participate, please follow the URL link below:

loginLink

We would greatly appreciate your participation in the survey by _DEADLINE DATE.

Your participation in this survey is voluntary and confidential. Each and every response is valued. To thank you for your participation, respondents who provide their contact information will be entered for a chance to win one of five $\$ 50$ gift certificates to Amazon.*

Additional details that influenced our design of recruitment emails included phrasing the subject line as a request for help, such as: "[Institution Name] School of Engineering needs your help" rather than an opportunity for alumni to share their opinions, e.g., "Share your thoughts..." (Trouteaud, 2004). We also purposely emphasized how their responses would not only result in changes at their alma mater but also contribute to a national conversation about how engineering education is taught. We solicited feedback from our alumni association partners on the recruitment text as well as our choice of incentives, recognizing their knowledge of what would resonate and be motivating to alumni to complete the survey.

\section{Incentives}

The incentives we had offered to undergraduate students to complete APPLES (e.g., \$4 via PayPal) and the response-boosting strategies we employed (e.g., targeting student listservs for engineering clubs and organizations, asking the engineering dean or some other recognizable campus figure to send the initial invitation, promoting the survey in person in required prerequisite engineering courses, etc.) would obviously not work for the alumni population. 
We had contemplated offering a drawing for one large prize (e.g. an iPad) per institution but ended up deciding on ten $\$ 50$ gift cards to Amazon (for a total of forty gift cards). Deutskens et al. (2004) showed that lotteries with small prizes but a higher chance of winning were most effective in increasing response rate in an online experimental setting. Another consideration that influenced our choice of multiple prizes of a lower value was concerns from our institutional review board policies regarding limits to payments made to human subjects where the incentive would be construed as income and require us to collect documentation of tax information such as Social Security Numbers, etc. The ease of purchasing and distributing the Amazon gift card awards to our drawing winners was also an important factor in our choice of incentive.

\section{Use of Reminders}

Follow-up contacts have been consistently reported as being the most powerful technique for increasing response rates, both in mail and online surveys (Buyer \& Miller, n.d.; Cook, et al., 2000; Dillman, 2000; Fox et al., 1988; Heberlein and Baumgartner, 1978; Schaefer and Dillman, 1998; Yammarino et al., 1991). However, according to Dillman (2000), crafting the right follow-up after the initial mailing is essential in order to maximize response rate. Through Qualtrics, we were able to determine which individuals: 1) had started the survey and completed it; 2) had started the survey without completing ${ }^{1}$; 3) had opened the survey without starting it; and 4) had not opened the survey at all. As a result, we were able to send more targeted reminders to only those who had not opened or completed the survey.

In designing the language for the reminders, we again emphasized alumni's connection to the institution and school of engineering as well as the importance of their input in a national conversation about reform in engineering education. We planned for two reminders within the 20 day survey window with the first reminder scheduled about halfway through the administration and the second reminder sent about three days before the close of the survey. Figure 3 illustrates the impact of these two reminders on the number of survey responses by day

\footnotetext{
${ }^{1}$ For individuals who had started the survey without completing it, we could also determine the page on which they left the survey.
} 
Figure 3. Average number of PEARS responses by deployment day

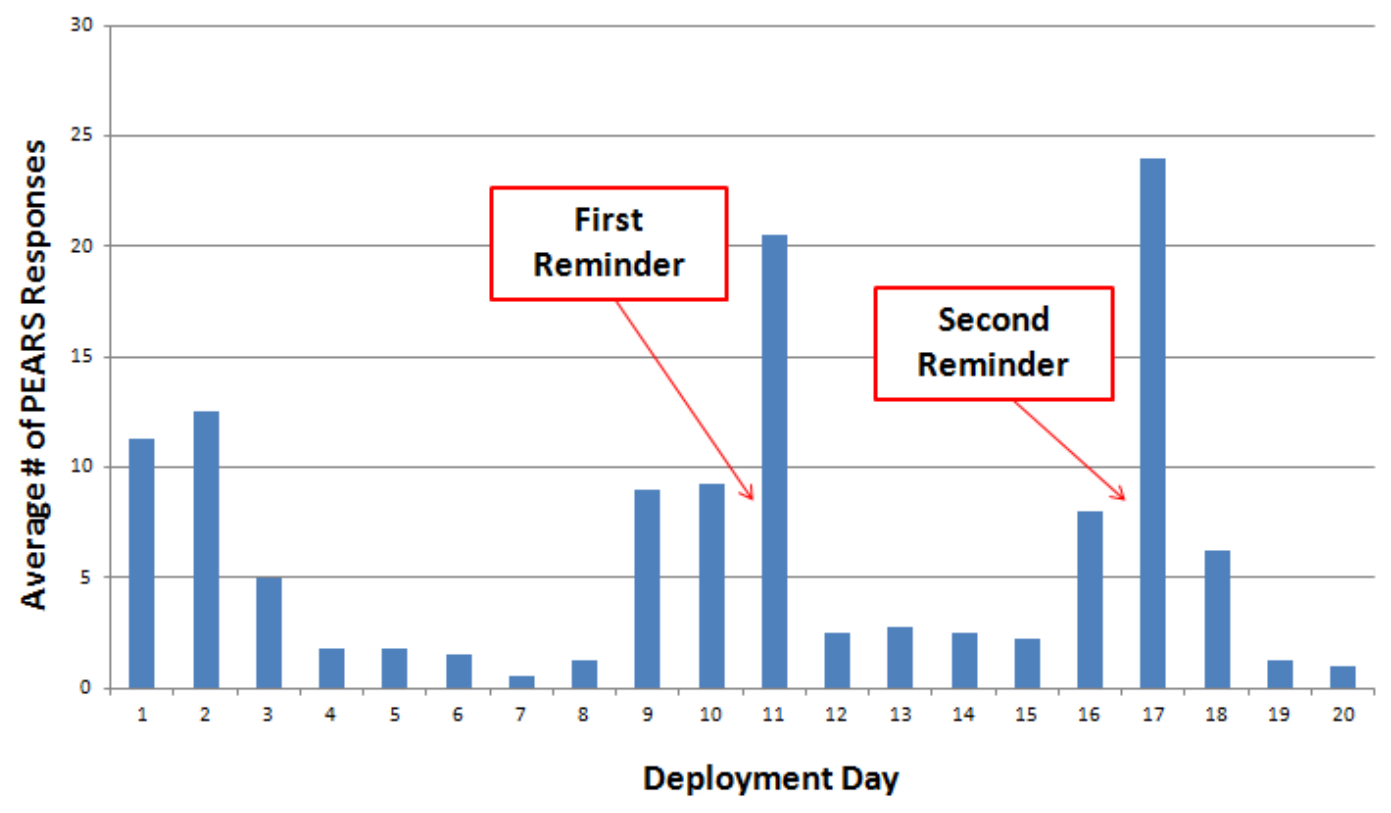

In his testing of how Internet-related strategies influence response rates to web-based surveys, Trouteaud (2004) had suggested that the time of day when the survey request is received should be taken into account. He showed that survey invitations received in the midday were less likely to be responded to as compared to those received in the early morning, perhaps due to competition with workload demands. We purposely varied the timing of our invitations and reminders both with respect to day of week as well as when it would arrive in people's email inboxes with the hopes of accommodating as many of the participants' schedules as possible.

Other features of the reminder email included mentioning that there was limited time to respond and in the second reminder sent a few days before the close of the survey, the text conveyed a strong sense of urgency or "last chance" to participate in the survey as well as in the drawing (Petrie, Moore, and Dillman, 1998). As seen in Figure 4, additional personalization of the email by major as well as calling out the graduating class of 2007 was incorporated, building upon Groves et al. (1992) who found that potential respondents can be persuaded to complete the survey if they know that other people similar to themselves have participated. 
Figure 4. Example of first reminder email

\section{Calling All [SCHOOL 1] Men and Women from the Year 2007!}

Dear [first name],

Remember your [School 1] days (and nights) as [name of major] major? Fast forward to what you're doing now. Whether it's in engineering or in something different altogether, we need to hear from you!

Not many [name of major] majors have responded yet to our Pathways of Engineering Alumni Research Survey (PEARS). This is a HUGE GAP in the data. We need YOUR voice. We need to learn from YOU what post-college life looks like for recent grads. This information is critical to help improve policy at Stanford and at the national level.

\section{Please take 15-20 minutes to participate in PEARS: [survey link]}

(If you have already started the survey, click the link to pick up where you left off.)

Feel free to email us at info@pearsurvey.stanford.edu to say hello and/or voiceyour suggestions for research like this in the future. It's the first of its kind. No one has looked at pathways of engineering alums like this before.

Reminder: by entering your contact information (separate from your survey data), you can enter a drawing for 5 Amazon gift cards valued at $\$ 50.00$ each. We are inviting only [School 1] engineering graduates from ' 07 to participate, so your chances of winning are good!

Thanks so much for your time, [first name].

[Name, title, and department of PI with link to faculty bio, photo, and school logo]

\section{Considering Sample Representativeness}

While much of the literature on both pen-and pencil as well as web- and internet-based surveys focus on strategies to increase response rates, Krosnick (1999), as cited in Cook, Heath, and Thompson (2000), reiterates the importance of sample representativeness:

But it is not necessarily true that representativeness increases monotonically with increasing response rate. . . recent research has shown that surveys with very low response rates can be more accurate than surveys with much higher response rates. (p. 540)

One challenge we faced from the very beginning of the deployment planning was simply defining and characterizing our survey population. We wanted to study students from the graduating class of 2007 which we defined as students who graduated in the calendar year of 
2007 (January to December). The characteristics of this population were determined from institutional data about this class (such as number of graduates by major/degree andgender) and further cross-checked with information from the ASEE College Profile database and the Integrated Postsecondary Education Data System (IPEDS). Our population was further narrowed since we only contacted alumni who had email addresses and who had agreed to be contacted by the university.

A second challenge was the possibility that email addresses would not be available for the entire population, which might introduce bias into the mail-out sample. Fortunately, at three of the four participating institutions, email addresses were available for $90 \%$ or more of alumni (as noted above, a small proportion of these email addresses were non-working at the time of deployment). At the fourth institution, emails were available for only $54 \%$ of the population; however, the distribution of this sample by gender and major (which institutions provided in addition to name and email address) indicated that the sample was fairly representative of the population on these dimensions. Institution- and respondent-level weights are being calculated to better approximate the survey responses had all graduates from the calendar year 2007 at each school responded to the survey, although such weights do not fully account for the more intangible forms of nonresponse bias in this type of survey work.

\section{Positioning PEARS in an Broader Context}

While PEARS was a single event, engaging alumni in a conversation about their undergraduate education and its relationship to their current work and careers should not be a one-off opportunity that happens once every five years. In order to leverage PEARS as a platform for ongoing discussion about engineering education at the institutional and national level, we built a website and set up an email address for interested alumni to continue to stay informed about the PEARS research and also stay in touch. Table 1 outlines some of the key topics and FAQs that were included in the PEARS website. 


\section{Table 1. Key Topics Addressed in the PEARS website}

PEARS 2011

What is PEARS about?

Purpose of research

Implementation as online survey

Deployment dates

Why is PEARS important?

Expected outcomes and impact

Importance of engineering/STEM education and related professions to national competitiveness, etc.

Who are the PEARS researchers?

List of PIs and a bit about their prior related research experience

Who is funding and supporting PEARS?

Who to contact for more information about PEARS?

\section{$\underline{\text { Participants }}$}

Who will be invited to participate?

How is participant safety and privacy assured?

What is an IRB?

Who to contact for more information about participation?

Name, email address

\section{Findings from PEARS Pilot Deployment}

Across the four institutions, response rates ranged from 16 to $32 \%$ with an average response rate of $28 \%$. This response rate was calculated based on the 543 responses resulting from the initial mail out to 1,896 email addresses. It should also be noted that the response rate based on the net mail-out (excluding the 95 bounce back emails) was $30 \%$.

Generally speaking, response rates for alumni surveys vary widely and our analysis team has been exploring ways of weighting the data to increase sample representativeness within in each institution. This approach is one example of more sophisticated analysis approaches being developed by applied survey researchers to address declining response rates.

In summary, the following are some practical recommendations for the logistics of designing a survey deployment plan:

- Establish partnerships with alumni associations and individuals or organizations that have insights into and existing relationships with alumni.

- When designing your survey administration plan, consider both the representativeness of your target sample as well as strategies to increase response rate.

- In your recruitment efforts, explore other options other than just email lists such social media and networking sites, face-to-face events, and disciplinary organizations and groups. 
- Incentives can be helpful but are certainly not the only motivator for alumni.

- Take into consideration the time of day when the survey invitations and reminders are sent and received.

- Take the time to draft and iterate on the text for the survey invitation, reminders, and other communications. Decide what to emphasize and where possible, pilot the text with representative alumni who can provide feedback on what components resonate with them and would motivate them to take your survey.

\section{Implications and Future Work}

As we continue to learn from our pilot of the PEARS instrument, several observations stood out as being important considerations for future iterations and administrations:

Advances in online survey technology played a critical role in our ability to successfully administer PEARS. We learned a great deal about the wide range of administration tools now available including message libraries and tracking of email histories. We also learned about additional features such as how to incorporate the demographic information (e.g., major/degree, gender) provided by each alumni association in to the survey administration tool in order to better support monitoring of returns and preparing the data for analysis. These features in addition to more sophisticated methods of data analysis will permit researchers to refine and improve upon this method of data collection for engineering alumni research.

The partnerships we established with each of the alumni associations also heightened our awareness of the alumni association as a stakeholder and potential audience for our emerging PEARS findings. While we have largely focused our dissemination efforts on School of Engineering faculty, chairs, and administrators, we are also planning to share our findings from the survey research as well as the deployment logistics to broader audiences such as alumni associations, career centers, and possibly institutional researchers. By soliciting their input and feedback on our findings we hope to maximize the utility and value of alumni research (Volkwein, 2010).

Given the increasing pressures of public accountability for higher education highlighted by Ewell (2005), alumni research such as PEARS and the Engineering Pathways Study will play a role in institutional and national policy decisions about engineering education. Effective use of thoughtfully designed alumni surveys will be crucial in these conversations around improvement and accountability (Borden, 2005).

Cabrera et al.'s (2005) review of alumni research also suggest that alumni surveys may be most impactful when they are incorporated into a comprehensive strategy for data collection that could begin when parents and children start to make plans for college. Findings about alumni from PEARS and the Engineering Pathways Study which build upon and potentially extend the research based on APPLES and the Academic Pathways Study on undergraduate experiences may be able to make this kind of contribution to the broader engineering education field. It is our hope that the findings from PEARS will contribute to the literature on the relationship between post-graduation work experiences and overall alumni satisfaction across various demographic groups. 


\section{Acknowledgements}

The authors would like to acknowledge support for several of the authors from Stanford University's Office of the Vice Provost for Undergraduate Education (VPUE) Summer Undergraduate Research Program and the Office of the Vice Provost of Graduate Education (VPGE) Graduate Fellowship Program. We also appreciate our collaboration with colleagues from the alumni association and research partners at each of the PEARS institutions.

This work was supported by the National Science Foundation (NSF) under grants 1022644and 0227558. Any opinions, findings and conclusions or recommendations expressed in this material are those of the authors and do not necessarily reflect the views of NSF.

\section{References}

Borden, V.M.H. (2005). Using alumni research to align program improvement with institutional accountability. New Directions for Institutional Research, 126, 61-72.

Buyer, L.S. \& Miller, K.J. (n.d.) Increasing survey response rates: Combining experimental manipulations. Retrieved March 19, 2012, from https://docs.google.com/viewer?a=v\&q=cache:EgrP6237otUJ:www.govst.edu/uploadedFiles/Institutional_Research/ Survey\%2520Response\%2520Rates\%25206.pdf+\&hl=en\&gl=us\&pid=bl\&srcid=ADGEESgXCHcRZHMa2HgJL6I m4E4LIArBAi6 qgOazdxPKNSRkSc0ANQFmVvWUbVFSAAwFZBPaQnH1qgipIPpGy2w4_Z_4JAZgdqnomSle N6jr2-nIEnVzValyb_mo9T2MhB-jnTj1TfW\&sig=AHIEtbRh-5HOn7ezW8KpHVe6bnlTIVnD9A\&pli=1

Cabrera, A.F., Weertz, D.J., \& Zulick, B.J. (2005). Making an impact with alumni surveys. New Directions for Institutional Research, 126, 5-17.

Chen, H.L., Donaldson, K., Eris, O., Chachra, D., Lichtenstein, G., Sheppard, S., \& Toye, G. (2008). From PIE to APPLES: The evolution of a survey instrument to explore engineering student pathways. In Proceedings of the American Society for Engineering Education Annual Conference and Exposition, Pittsburgh, Pennsylvania.

Cook, C., Heath, F. \& Thompson, R.L. (2000). A meta-analysis of response rates in web-or internet-based surveys. Educational and Psychological Measurement, 60(6), 821-836.

Deutskens, E., De Ruyter, K., Wetzels, M., and Oosterveld, P. (2004). Response rate and response quality of internet-based surveys: An experimental study. Marketing Letters, 15(1), 21-36. Retrieved March 19, 2012 from http://arno.unimaas.nl/show.cgi?fid=2724

Dillman, D.A. (2000). Mail and Internet Surveys: The Tailored Design Method. New York: Wiley.

Donaldson, K., Chen, H., Toye, G., \& Sheppard, S.D. (2007). Targeting undergraduate students for surveys: Lessons from the Academic Pathways of People Learning Engineering Survey (APPLES). In Proceedings of the Frontiers in Education Annual Conference and Exposition, Milwaukee, Wisconsin.

Donaldson, K., Chen, H.L., Toye, G., Clark, M., \& Sheppard, S. (2008). Scaling up: Taking the Academic Pathways of People Learning Engineering Survey (APPLES) National. In Proceedings of the ASEE/ISEE Frontiers in Education Conference, Saratoga Springs, NY, October 22-25, 2008. 
Ewell, P.T. (2005). Alumni studies as instruments of public policy: The U.S. experience. New Directions for Institutional Research, 126, 19-29.

Fox, R. J., Crask, M. R., \& Jonghoon, K. (1988). Mail survey response rate: A meta-analysis of Selected techniques for inducing response. Public Opinion Quarterly, 52, 467-491.

Groves, R.M., Cialdini, R.B., \& Couper, M.P. (1992). Understanding the decision to participate in a survey. Public Opinion Quarterly, 56, 475-495.

Heberlein, T. A., \& Baumgartner, R. (1978). Factors affecting response rates to mailed questionnaires: A quantitative analysis of the published literature. American Sociological Review, 43, 447-462.

Joinson, A.N. \& Reips, U.D. (2007). Personalized salutation, power of sender and response rates to Web-based surveys. Computers in Human Behavior. 23 (3): 1372-1383. Retrieved March 19, 2012 from http://www.sciencedirect.com/science/article/pii/S0747563204002304

Krosnick, J. (1999). Survey research. Annual Review of Psychology, 50, 537-567.

Olsen, D. (2000). Institutional research. New Directions for Institutional Research, 111, 103-111.

Peltz, J. (2012, January 7). For some consumers, surveys breed feedback fatigue. Mercury News.com. Retrieved January 8, 2012 from http://www.mercurynews.com/rss/ci_19696221

Perkins, R.A. (2011). Using research-based practices to increase response rates of web-based surveys. EDUCAUSE Quarterly Magazine, 34(2). Retrieved January 8, 2012 from http://www.educause.edu/EDUCAUSE+Quarterly/EDUCAUSEQuarterlyMagazineVolum/UsingResearchBasedPra cticestoI/230534

Petrie, R., Moore, D.L., \& Dillman, D.A. (1998). Establishment surveys. The effect of multi-mode sequences on response rates. Proceedings of Survey Methods Section (pp. 981-987). Alexandria, VA: American Statistical Association.

Pike, G.R. (1994). The relationship between alumni satisfaction and work experiences. (1994). Research in Higher Education, 35(1), 105-123.

Porter, SR. (2005). Survey research policies: An emerging issue for higher education. Directions for Institutional Research, 127, 5-15.

Schaefer, D.R. \& Dillman, D.A. (1998). Development of a standard e-mail methodology. Public Opinion Quarterly, 62, 378-397.

Trouteaud, A.R. (2004). How you ask counts: A test of internet-related components of response rates to a web-based survey. Social Science Computer Review, 22(3), 385-392.

Volkwein, J.F. (2010). Assessing alumni outcomes. New Directions for Institutional Research, S1, 125-139.

Yammarino, F. J., Skinner, S. J., \& Childers, T. L. (1991). Understanding mailed survey response behavior: A meta-analysis. Public Opinion Quarterly, 55, 613-639. 